\title{
'EMI Is a War' - Lecturers' Practices of, and Insights Into English Medium Instruction Within the Context of Sri Lankan Higher Education
}

\author{
Chitra Jayathilake \\ Department of English and Linguistics, University of Sri Jayewardenepura, Sri Lanka \\ Sujeewa Hettiarachchi \\ Department of English and Linguistics, University of Sri Jayewardenepura, Sri Lanka \\ Sujeeva S. Pereira \\ Department of English and Linguistics, University of Sri Jayewardenepura, Sri Lanka
}

\begin{abstract}
English Medium Instruction (EMI) is a growing educational praxis in the world. Sri Lanka also practises EMI in primary, secondary and university education contexts. Nevertheless, EMI is not adequately researched: the existing scholarship alludes to the significance of its context-dependency (e.g., Snchez-Prez, Maria del Mar 2020). Moreover, there is a lacuna of scholarly knowledge of how EMI works in Sri Lankan educational contexts. Hence, this exploratory study examined lecturers' practices of, and insights into, EMI within the context of Sri Lankan higher education. The data were drawn from in-depth qualitative interviews with ten lecturers who teach Social Sciences through EMI at three state universities in the country. Interviewees - encompassing males and females and belonging to varying age groups - have a range of EMI teaching experience and different professional and educational qualifications. Qualitative thematic analysis was utilised to uncover themes related to EMI in the data. Findings disclose a few issues and problems associated with EMI. They underscore the belief that EMI enhances L2 (Second Language) proficiency, thus creating a space for job opportunities for undergraduates, and higher education and professional development for both lecturers and students. Nevertheless, EMI is problematic mainly due to (i) low L2 proficiency in both lecturers and students, (ii) lecturers' inconsistent praxis in assessing and teaching students, (iii) the shortage of training programmes on EMI, and (iv) arbitrary administration issues including the recruitment of EMI lecturers. The paper provides insights into EMI implementation in English as L2 contexts and adds new vocabulary to EMI praxis and research.
\end{abstract}

Index Terms-EMI, interview, thematic analysis, perception, Sinhala, L1 and L2

\section{INTRODUCTION}

English has been at the centre of numerous globalisation mechanisms since the late $20^{\text {th }}$ century. It is considered the language of opportunity, thus as pivotal in relation to the progress of, inter alia, technology, business, medicine, internationalisation and education. Given that, the use of English as a medium of instruction for educational purposes regardless of what language/s learners speak as of their First Language (L1) - has become a common currency in many non-English speaking countries, both in the once-colonised countries by the British, and/or in the developing countries (Coleman, 2006; Wa“chter \& Maiworm, 2008). Countries, where English lacks any official recognition, also offer courses in the medium of English endorsing the 'coveted internationalisation' through higher education (Llurda, 2013, p. 497). Accordingly, English Medium Instruction, henceforth EMI - meaning, English as the medium of instruction in contexts where English is not commonly spoken (Dearden \& Macaro, 2016) - has been a burgeoning educational praxis. Sri Lanka has also been in this practice of EMI, not only in primary and secondary education contexts, but also in universities since the 1990s.

Language Use in Sri Lanka

English is the link language in Sri Lanka, while Sinhala and Tamil are the two national languages. Closely consistent with the population, literacy rates in Sinhala and Tamil languages (Figure 1) are $81.8 \%$ and 14.9\% respectively: approximately $17 \%$ of the population can read and write English while only about $13 \%$ of the population can speak English (Department of Census and Statistics, 2014). 


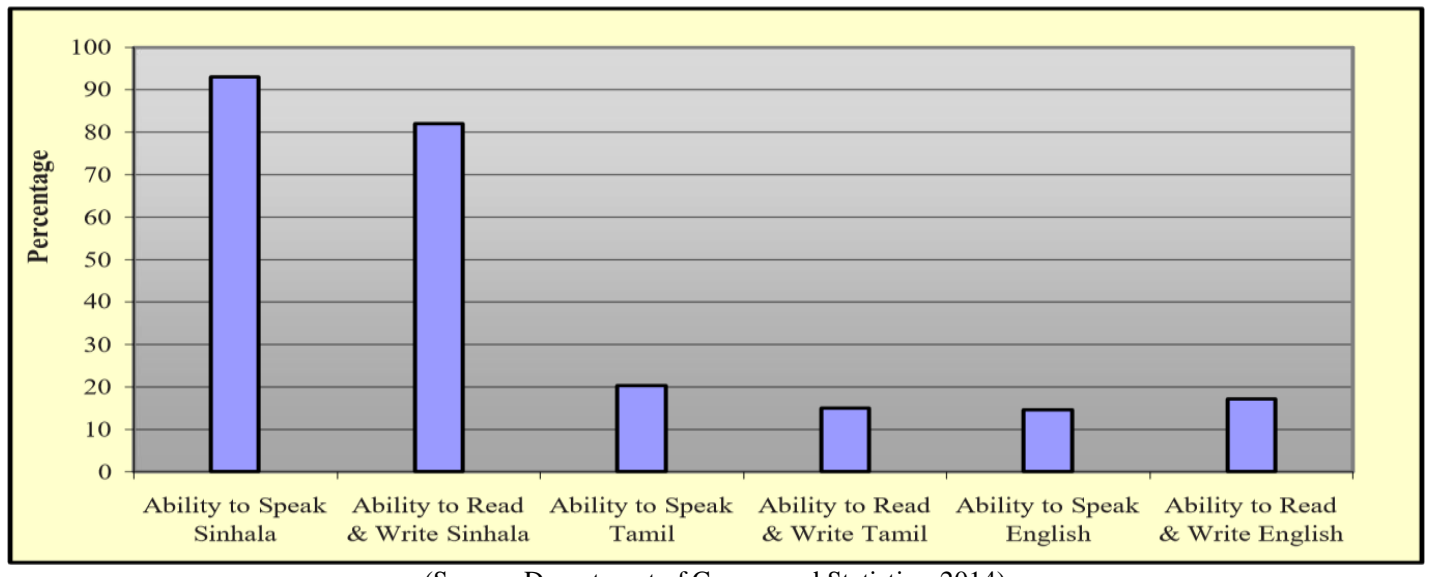

(Source: Department of Census and Statistics, 2014)

Figure One Language Use in Sri Lanka

Although English is taught as a compulsory subject (as a Second Language) from Grade 3 (at the age of 8 years) onwards in schools, only about $50 \%$ of candidates have been securing pass grades at the General Certificate of Education (Ordinary Level) examination for three decades (Department of Examinations of Sri Lanka). Moreover, regarding English skills, Sri Lanka has secured only the $78^{\text {th }}$ position out of 100 countries in the world and the $18^{\text {th }}$ out of 28 countries in Asia (Global Ranking of Countries and Regions, 2019). Evidently, Sri Lankans' English skills have been at a low ebb for decades.

It is against this backdrop that the state universities in Sri Lanka offer EMI classes. In line with the policy of 'free education' in Sri Lanka, the cost for undergraduate education in state universities is borne by the government, hence, the admission of undergraduates is limited, based on students' Z-score values, merit and district quota (Universities Act, 1978). As per the University Act, the Minister of Higher Education has the authority to decide on the medium of instruction at state universities: nevertheless, each university, as 'autonomous bodies', can exercise its discretion regarding EMI implementation and praxis (Attanayake, 2017, 91).

At the dawn of independence from the British administration, EMI was confined to Medical, Engineering and Science Faculties at Sri Lankan state universities. Since the beginning of the $21^{\text {st }}$ century, EMI has been practised even in the Faculties of Humanities and Social Sciences of universities, which have traditionally relied on Sinhala or Tamil as their primary medium of instruction. Evidently, EMI is swiftly outspread to domains where national languages have been the focus. Therefore, EMI warrants research: this study explores lecturers' practices of, and insights into English medium instruction in selected state universities.

\section{REVIEW OF LITERATURE}

EMI is relatively a new research topic: only a single scientific study had been in existence on EMI prior to 2000, which is Vinke's (1995) study from the Netherlands which underscored the significance of Mother Tongue (MT) in lecture comprehension (Macaro, Curle, Pun, An \& Dearden, 2018). Maiworm \& W“achter's (2002) study is the first to explore the growth of English-taught programmes in Europe, while Dearden's (2015) study is the first to map the global expansion of EMI. Given the exponential growth of EMI since the early $21^{\text {st }}$ century, the overall EMI implementation picture has been the focus in scholarship (Ammon \& McConnell, 2002; Maiworm \& Wa"chter, 2002; Macaro et al., 2018; Wa“chter and Maiworm, 2008).

EMI is frequently adopted in countries where the national language is not widely spoken, such as the Netherlands, Germany, Finland, and Sweden (Byun, 2011). It has also been widespread in Asia (Naun, 2003), especially in former British colonies such as India, Singapore, Malaysia, and Hong Kong (Altbach 2004). EMI is a means to cope with internationalisation in Asian countries such as China, Japan and Korea (Lassegard 2006; Manakul, 2007; Tsuneyoshi, 2005; Yumei 2010). For instance, along the lines of internationalisation, EMI is a 'strategic response to the increasingly competitive academic market' (Kim \& Tarter, 2018, p. 403), a window for innovation (Byun et al., 2011), a path for future prospects (Collins, 2010) and academic disciplinary requirements (Evans \& Morrison, 2011).

Nevertheless, the implementation of EMI programmes is not without challenges and negative effects, as disclosed through many meticulous case studies, which have shown both analogous and disparate results. EMI programmes in China and Japan are promoted by the governments (Macaro et al., 2018), while Taiwanese universities have initiated EMI without the government's top-down policy (Yang 2015). Teachers' and students' English language proficiency is not a crucial obstacle in European universities (Maiworm \& Wa“chter 2002; Wa“chter and Maiworm 2008), although Erling and Hilgendorf's (2006) study of a German university attests it otherwise. Students' low proficiency in English is a barrier to comprehension of the subject content (e.g., Belhiah \& Elhami, 2015; Goodman, 2014; Huang, 2015; Soruç \& Griffiths, 2018). This leads EMI lecturers to focus on the content, ignoring the language, as revealed through Roothooft's (2019) comparative study of Humanities and STEM (Science, Technology, Engineering, and Mathematics) 
in a Spanish context.

Further, Zhang (2017) uncovers that the current main problem in China's EMI policies lies in non-English speaking lecturers' language practices. Lecturers' subject knowledge and English language proficiency are equally important for the success of EMI (Hoare, 2003; Kirkgöz, 2005, 2013; Sert, 2008). Further, Tsuneyoshi's (2005) study of a University in Tokyo shows the insufficient assistance for language development as a barrier for EMI. It adds that insufficiency in securing capable lecturers in EMI and lack of proper compensation for EMI lecturers who take the challenge are constraints. The lack of interaction between teachers and students, and scarcity of feedback in EMI classes (Kang \& Park, (2004) are also main obstacles for EMI. Despite Airey's $(2012,2020)$ suggestion that content lecturers should reflect on their students' linguistic goals, lecturers' inadequate English language competency is a hindrance to achieving it. Accordingly, inadequate language competence is the main obstacle to both acquire and/or disseminate the content knowledge correctly.

Comparative studies on EMI and students' L1 also have added much insight to the existing scholarship on EMI. L1 is more useful both in comprehending the information and in gaining conceptual insights of the content (Coşkun, et al., (2014), and in sustaining the knowledge (Kırkgöz, 2014) than an L2. Three common negative EMI characteristics are (i) lack of interaction between students and teachers, when non-English speaking teachers conduct EMI classes (Airey \& Linder 2006), (ii) less coverage of syllabi (Klaassen \& Graaff, 2001; Vinke et al., 1998), and (iii) lack of efficiency and professionalism in disseminating knowledge (Sert, 2008; Vinke et al. 1998). EMI creates negative effects on nonEnglish speaking teachers and/or L1 (e.g., Hoare, 2003; Klaassen \& De Graaff, 2001; Kırkgöz, 2005). It creates the potential to distance one from his/her national language (Kırkgöz, 2005), and to develop Mother Tongue attrition and cultural identity loss (Smith, 2004), resulting in 'linguistic genocide' (Skutnabb-Kangas, 2000, 174). Despite the growth of EMI, it is also not without resistance (Macaro et al, 2018).

While EMI in Asian countries is under-researched (Byun, 2011), there is a dearth of research on EMI in Sri Lanka. Wedikkarage (2009) highlights that EMI is solely an authoritative and administrative decision in Sri Lankan school contexts, and a failure due to the lack of language proficiency: neither the teachers nor the students are 'comfortable,' and only 7\% of the population, in general, are competent in English (2009: 264). Concurring with Wedikkarage's study, Medawattegedera (2011) reveals - through an ethnographic case study of EMI science classes in four schools in Sri Lankan public schools - a considerable discrepancy between policy and practice and a variation of policy implementation across different school types. Nevertheless, she argues for the acceptance of code-switching as a pragmatic approach in schools to overcome the language issue. Consonant with Collins' (2010) study, Thirunavukkarsu's (2012) study conducted in a district (where the Tamil language is predominantly used) in Sri Lanka reiterates the necessity of EMI as a route to enhance English skills, and for upward social mobility. In line with Dearden's (2015) study of 60 countries, including Sri Lanka, there is a trend towards EMI backed by the government: yet, as she contends there is the potential for the national languages to be undermined.

Research findings on EMI are inconsistent: whether EMI enhances or downgrades the educational outcomes is unresolved (Berriz, 2006; Graddol, 2005, 2006; Wright, 2004). Given the diversity in research findings, the paucity of Sri Lankan contexts, and the lacuna of a single study on Sri Lankan university lecturers' perceptions on and practices, EMI warrants research on this global phenomenon.

Research objective

The exploratory study aimed to examine the lecturers' practices of, and perceptions on EMI from state universities in Sri Lanka, seeking to answer: (i) lecturers' experiences and the role as practitioners of EMI, (ii) what challenges and issues they encounter in practicing EMI, and (iii) what they have observed in students in EMI classes by utilising indepth interviews.

\section{MeTHODOLOGY}

\section{A. Study Context}

The research was conducted at three state universities in Sri Lanka. Each gained its university status in 1958, 1995 and 1996 respectively, and currently practise EMI in subjects of humanities and social sciences. Undergraduate education is state-funded and offered free of charge in these universities. The student population (as internal students) pursuing subjects in humanities and social sciences in these three universities is 6000 approximately.

\section{B. Participants}

\section{Interviewees}

Interviewees include ten EMI university lecturers. The group of interviewees (Table 1) - who encompass both males and females, belonging to varying age categories - have a range of university teaching experience and different professional and educational qualifications. The selection of the interviewees was based on the prior information collected through a questionnaire from all the lecturers who teach subjects related to humanities and social sciences in EMI in the three universities concerned. Ten interviewees, who conduct lectures both in English and Sinhala were included for their comprehensive views on EMI. Henceforth, they are identified with pseudonyms: Ranjith, Rangga, Chapa, Pathum, Mahela, Geetha, Namal, Pavani, Bandara and Rosy. 


$\begin{array}{cccc}\text { TABLE ONE } \\ \text { Name } & \begin{array}{c}\text { PROFILE OF THE INTERVIEWEES } \\ \text { Age group }\end{array} & \text { Gender } & \begin{array}{c}\text { Teaching experience by } \\ \text { years (appr.) }\end{array} \\ \text { Ranjith } & 40-45 & \text { Male } & 18 \\ \text { Rangga } & 50-55 & \text { Male } & 20 \\ \text { Chapa } & 45-50 & \text { Female } & 20 \\ \text { Pathum } & 55-60 & \text { Male } & 18 \\ \text { Mahela } & 55-60 & \text { Male } & 26 \\ \text { Geetha } & 35-40 & \text { Female } & 8-9 \\ \text { Namal } & 35-40 & \text { Male } & 8-9 \\ \text { Pavani } & 40-45 & \text { Female } & 12 \\ \text { Rosy } & 35-40 & \text { Female } & 8-9 \\ \text { Bandara } & 30-35 & \text { Male } & 5\end{array}$

\section{Interviewers-Cum-Researchers}

The information collected from interviews is considered as edifices; hence, it is imperative to provide an explanation of the researchers' relationship to English. Interviewers-cum-researchers - two females and one male - are non-native speakers of English and are Senior Lecturers at a Department of English at a state university in Sri Lanka. None of them is an EMI lecturer, yet each holds more than 18 years of experience in teaching English to undergraduates.

\section{Data Collection and Analysis}

A qualitative interview paradigm was employed to collect data by visiting all three universities. As per the ethical considerations, formal consent was sought from the participants and the universities; their right of withdrawal was given at any point without any negative consequences, and anonymity and confidentiality were assured. Each lecturer was interviewed in-depth, and face-to-face for approximately 60 minutes using a semi-structured interview format. Each participant was given the interview schedule in advance and was informed of the focus and the data collection stratagem. With a view to obtaining a better in-depth understanding of EMI, they were expected to use either English or Sinhala for the conversation, and assurance was given that their English proficiency would not be judged. The interview included the following questions, albeit unrestricted and interactive.

(1) How did you enter EMI?

(2) How do you position your English language proficiency/English background to teach in English?

(3) Do you follow any special teaching strategies in EMI classrooms?

(4) Are there any differences in teaching in EMI and in L1 classrooms?

(5) Are you concerned with students' language acquisition in EMI classrooms?

(6) Do you assess students in EMI and Sinhala/Tamil medium classrooms in the same way?

(7) What issues do you face in EMI classes, if any?

(8) Do you think EMI improves students' English proficiency English?

A qualitative thematic analysis (Guest, G. et. al. 2012) was used to examine and identify different patterns of meaning across the collected data, transcribed verbatim, through a rigorous process of data familiarization.

\section{RESUlTs AND DiscusSiON}

The findings of the current study are organised under five main themes as presented in Figure 2.

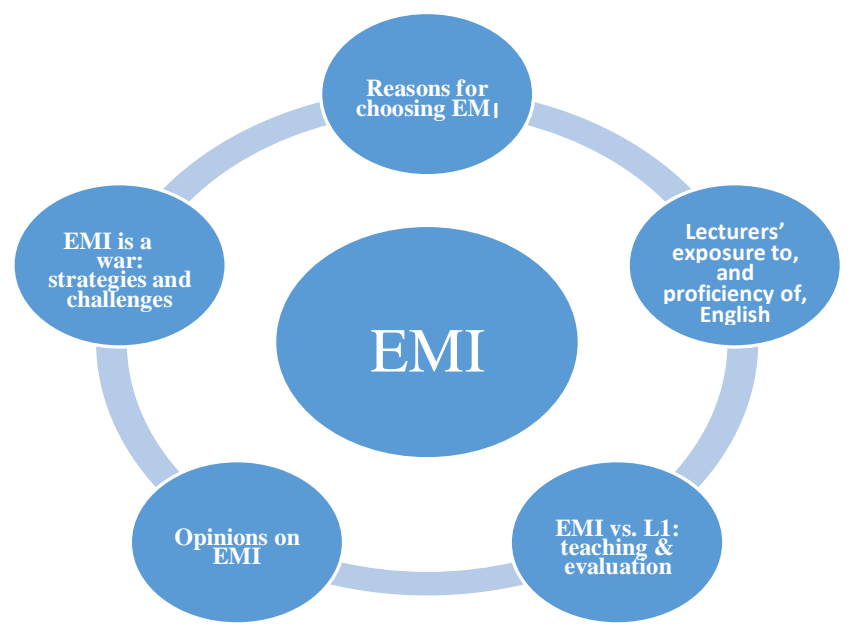

Figure Two Findings-Emergent Themes 


\section{A. Lecturers' Exposure to, and Proficiency of, English}

A preliminary finding of this study was the lecturers' positioning of their exposure to, and proficiency of, English. The ascending order of language competence followed in the study is as follows: poor; fair; average; good; very good and excellent. Each participant's L1 is Sinhala. Nine of them revealed the dearth of exposure to English in their home contexts: Namal overtly stated 'both my mother and father can't write or read anything, even in Sinhala'. Each participant's primary and secondary education had been in Sinhala. Except for Chapa, others confirmed that their English language competence was 'very poor' at schools. Each participant had obtained his/her first degree from a Sri Lankan state university: six in Sinhala and four in English. Nine participants have obtained at least one postgraduate degree in the medium of English. As at the beginning of their EMI career, or prior to their postgraduate studies, each sans Chapa positioned his/her English language competence either as 'poor' or as 'fair.' Only Chapa rated her current competence in English as 'very good,' while nine positioned it as 'average': in other words, coinciding with Jiang et al. (2019), all participants currently positioned themselves as capable of using English to present subject knowledge. Nevertheless, many of them expressed their lack of confidence regarding English skills, for instance, as overtly expressed by Pavani: 'I don't think I have the capacity [original emphasis] to teach in English'.

The common consensus is that those who have higher exposure to English will acquire the language better, and will communicate better; hence, they will disseminate correctly and confidently the content of the subject in EMI (e.g., Erling \& Hilgendorf, 2006; Jiang et al., 2019). In view of that, whether many members in the current study adequately disseminate the expected content knowledge and develop skills in EMI classes, especially in subjects of humanities and social sciences, is skeptical. This concurs with the findings of Asian EMI contexts where English is not used as an L1 (Erling \& Hilgendorf, 2006; Maiworm \& Wa "chter, 2002).

\section{B. Reasons for Choosing EMI}

The commitment to the career is generally perceived as the main reason for entering the teaching profession (Cole, 1985; Hansen, 1995). Nevertheless, findings of this study revealed that it is deviant, and three-fold: (i) institutional decision enforced on lecturers (ii) social prestige and personal benefits for lecturers because of English, and (iii) subject related requirements.

\section{Institutional Decision Enforced on Lecturers}

Five participants overtly revealed that they were unexpectedly enforced into EMI by the university authorities, the Vice-chancellors, and the Deans, either at the recruitment interviews or during the probationary period of their profession, as elaborated in the different excerpts given below.

Our Vice-chancellor "straight" asked us to do EMI ... we were "forced" to take EMI classes during our probationary period. The Dean also asked us to teach by "using our little knowledge" of English. He said we needed to produce graduates who would "know some English" so it would be "our victory". (Mahela)

When we entered the university [for recruitment interviews], we were asked whether we could teach in English. If we had said "no", we wouldn't have been selected. (Namal)

Only when the [faculty] prospectus was given, I got to know that I had to teach in English. (Pavani)

It was a decision thrust on me. (Rosy)

I would be "lying" if I said I did EMI classes "willingly" (Pathum)

We were influenced to teach in English by "rote learning" of lessons... some [were] successful, some failed. (Mahela)

Rangga also recalled how he implemented EMI in his Department during his tenure as the Head in 2014. This apparently was an impromptu Department decision taken by the Head, not a forceful thrust by the Vice Chancellor.

Evidently, most lecturers have been forcefully taken into EMI programmes. Hence, the reasons for entering EMI cannot be perceived as lecturers' commitment to the profession, but their subjection to the force of circumstances by the authority.

\section{Social Prestige, and Personal Benefits and Preference}

Except for Chapa, all others either implicitly or explicitly expressed that EMI is beneficial to enhance their own English skills and to gain social prestige. They could improve their English skills by being in EMI programmes and consequently they could gain academic qualifications related to the English language.

I'm happy to teach in English for two reasons. It gives an opportunity for us to improve our English, ... students will also get the opportunity to improve their English; so willingly or unwillingly teaching in English is important. (Rosy)

Pavani implied that EMI is beneficial to obtain International English Language Testing System (IELTS) qualification, hence, to expedite the path for her higher education scholarship. Meanwhile, the reasons for Chapa's and Rosy's preference to teach in EMI to L1 classes are twofold: Chapa stated that she feels more confident and comfortable in teaching in English, while Rosy recollected that she was a graduate of EMI in her BA Degree, hence, she prefers English to L1 for teaching. Ostensibly, despite the initial forceful engagement in EMI, lecturers currently engage in EMI willingly, as English skills are perceived to be obligatory for socio-economic progression, consonant with previous 
studies (Farrell \& Giri, 2011; Hornberger \& Vaish, 2009; Phillipson, 2001; Stroud \& Wee, 2005). Hence, it was sociocultural and educational demand associated with the English language which allowed lecturers to take advantage of the opportunities that presented themselves, even though by the authority.

\section{Subject-Related Terminology Requirements}

Two participants stated that English is required to teach some science-related subjects as there are no Sinhala equivalents for some terminology. However, unlike technical subjects like mathematics and computer engineering, the overall aim of the humanities and social sciences is to empower students with a wider knowledge and skills to gain a pluralistic view of human problems and society. Hence, language competence should not be confined to the delineation of terminology, which requires future research.

\section{C. 'EMI is a War': Strategies and Challenges}

Noticeable pragmatic strategies and challenges in EMI are reported below with excerpts depicting separate circumstances - both recurring and isolated features. They can be summed up in the metaphor used by Mahela: 'EMI is a war for teachers and students as both were in the same boat' regarding English. All the participants with no hesitation admitted that their EMI teaching greatly depends on the PowerPoint slides prepared in advance.

Given the unfamiliarity and limited competence in English, lecturers have to spend much time and effort in preparing for EMI, including the notes to be read out in class, and the sentences needed to explain the PowerPoint slides and the lesson. Evidently, EMI teaching is often at the mercy of the PowerPoint slides, hence problematizes the students' conceptualisation of the content of the subjects. The following excerpts provide detailed testimony.

When I do a presentation... PowerPoint in English. I remember now... at the beginning of my EMI, I used to write down "all what I would say in class". I "write from A to Z of what I tell the students". I didn't mean that I read out all what I wrote, but "I write all". (Pavani)

We ... keeping dictionaries near us ... staying up all night...that's how we did, ...that's how we tried, even now... I do it for 2- 6 hours for a session, excluding the [time taken to prepare notes. (Mahela)

My "mouth aches" from the reading for two hours. I must read out the slides and display them...have to prepare notes for the ones I don't not read out. It's such a "trouble". (Rosy)

All unanimously agreed that the interaction in EMI classrooms in English-be they teacher-students or among students - was highly limited. Of the random interaction in class, most were teacher-initiated between the teacher and the whole class. The major reason is the language weakness both in lecturers and students. As such, most of the participants agreed that they were not resistant to students' usage of L1 for any interaction, while five of the interviewees admitted that bilingualism is welcome in classrooms. For instance, Bandara stated, 'Students often ask questions in Sinhala in EMI classes.' Mahela revealed how L1 was used for the dissemination of the EMI lesson. 'We used both English and Sinhala at the beginning of our EMI classes. During a two-hour session, we used to teach only for 20 minutes in English. The rest was conducted in Sinhala. It is a common understanding that English should be considered as the language of communication for all EMI-related activities: the delivery of lectures, students' group work, the teacher-student interaction, the student-student interaction, classroom group discussions, and formative and summative assessments. Nevertheless, the actual use of English in EMI classrooms is often confined to the reading of PowerPoint slides and the teacher-prepared notes.

What is also implicitly reflected through participants' strenuous exclusive preparation is EMI lecturers' lack of communication power in English, in contrast to the findings of previous studies (Björkman 2009; Kaur 2009; Mauranen 2009). As rightly noted by Doiz and Lasagabaste (2020), EMI in our study is also an 'onerous' task for many lecturers. To disseminate knowledge properly, language issues in EMI should be addressed in a more integrated and comprehensive way (Doiz and Lasagabaster, 2020). Nevertheless, EMI reduced lecturers' abilities to improvise and to express their subject knowledge clearly and accurately.

The major problem in this regard lies in the process of recruitment of lecturers for EMI. Despite their [relatively] poor English language proficiency, and lack of confidence to teach in English, EMI is a direct or indirect thrust on the lecturers. Moreover, despite the suggestion that all EMI lecturers should reflect on the linguistic goals of their students (e.g., Airey, 2012, and 2020), our study reports it slightly differently, as the English language was a communication hurdle for the majority of the participants themselves.

However, many of the participants considered it their duty or responsibility to teach English: the reasons apparently are three-fold: (i) lecturers' own lack of competence in English (nine out of ten participants), (ii) the absence of skills to teach English and (iii) the feasibility aspects such as insufficient time. Many of them often define the subject-specific terminology, while only Bandara admitted his efforts to teach English: 'I teach English to students during lectures ... take about half an hour and teach English, ...especially tenses, simple grammar points and sentence patterns'. Yet, all these teaching gestures are only for the purpose of enabling content communication.

Moreover, the lecturers taken for the study practised stratagem of somewhat varied quality: modified teacher talk, group activities, extracurricular activities in English and extension of lecture duration. To eliminate students' language barrier, Chapa employs modified teacher talk when clarifying the content, while Rangga includes writing activities in English during lectures, as demonstrated through the following excerpts.

I speak in English "slowly" for the English medium students... I always try to use "simple English" ...I just 
don't want to use very "big words". (Chapa)

One teaching technique I do is .... after about half an hour, I give students some "writing activities". Unlike students in L1 class, students in EMI are "weak" ... They "can't write". So, I sometimes give them some "samples". (Rangga)

Referring to a personal anecdote, Chapa stated the necessity and significance of student-led activities through EMI despite students' language barriers.

Students are really catching up the language and the subject, because... I'm an example for that also, whatever I did at home... when I came first year to the campus and started learning in English its completely different. I was thousand times better during my final year than my first year... teaching methods really matter here. (Chapa)

What was also noticed from three other lecturers is the way they motivate students to engage in extra-curricular activities in English. For instance, Pavani stated, 'We have a society called Nature Club. We ask students to take down the minutes [of the meetings] in English. So, they can develop their English'. Besides, Rangga stated that he doubles the duration of his EMI lectures, not the L1 instruction classes. This bears a close resemblance to the findings from two other lecturers.

Generally, for my EMI lectures, I double the usual time... I take four hours to do a two-hour lecture...because its time consuming when I do extra activities. In Sinhala medium classes, it is only the explanation. (Rangga)

Further, the study also revealed how linguistic challenges in EMI can result in psychological challenges. For instance, Namal narrated how 'a senior experienced lecturer was shivering [original emphasis] while conducting an EMI session.' Mahela also expressed how he feels less confident in EMI classes: 'explaining the subject matter is ok now but going beyond that...I am scared [original emphasis] to tell a joke [in English], if students laugh at me.' This inconsistently alludes to the contention that telling jokes and personal anecdotes in L1 is helpful to build rapport with the students and sustain their attention (Kim \& Tatar, 2017). Mahela also recalled whenever he made language blunders in EMI classes, he was 'upset' and 'confused' and it took about '20 minutes' from the session for him to recover from the psychological trauma. Such circumstances problematise as to whether and how the students have gained the content knowledge along the lecturers' continuum of L1 acquisition.

Given the lack of competence in English, lecturers attempt to facilitate teaching and classroom interaction through some strategies. Such approaches are mainly three-fold, albeit in different quantities (i) by accommodating bilingualism - incorporating students and lecturers' first language through code-switching or code-mixing; (ii) rephrasing and repeating the presentation of lectures, and (iii) expanding lecture duration. The recurrent strategy that the majority practised was the use of bilingualism. In learning unfamiliar and complex subject knowledge in EMI contexts, as posited in literature (Toribio 2004; Ong et al., 2013), students' cognitive capacity is challenged both by the content and the language. To assist students' comprehension and to eliminate nonunderstanding, strategies such as code switching and code mixing can be productive, as suggested by Medawattegedara (2011). L1 in EMI contexts is 'crucial for social and instructional purposes and for their own time management' (Kim \& Tatar, 2017, p. 157). However, in the current study, meaning construction and transmission in this way depended mainly on written texts on the PowerPoint slides, for instance, learners' reading comprehension skills in English.

To reiterate, for subjects in humanities and social sciences, semantics is also pivotal, as they aim to offer pluralistic views of society. Besides, modified teacher-talk paves the way for effective communication, which is congruent with previous research findings (Björkman 2011 \& Jian 2019). It enhances intelligibility in EMI class, and may have compensated for participants' insufficient English competence. Nonetheless, it is problematic because many lecturers in our study focused on lexical issues, especially in subject-specific terminology, giving less or no attention to semantic, logical, and grammatical issues. Strategies used in this manner may be more aptly useful for technical subjects such as science, medicine and engineering (Meierkord, 2013), rather than for the subjects of humanities and social sciences, which largely depend not only on technical terms but also on the conceptual descriptions. This exploration resonates with what is reported in Basturkmen \& Shackleford's (2015) studies: they highlighted the instances where EMI lecturers largely neglect, grammatical, and discourse features, which are essential to developing proper comprehension and the accurate presentation of the content.

\section{EMI vs. L1: Teaching and Evaluation}

Regarding the comparative experiences in EMI and L1 classes, teaching and evaluation practices are significant. The recurring feature in teaching praxis is that lecturers never prepare any PowerPoint slides for L1 classes but use the same prepared in English for EMI classes. In other words, Sinhala medium PowerPoint slides have never been prepared for L1 classes due to two reasons: (i) to make students in L1 classes also exposed to English, and (ii) to reduce the workload on lecturers in preparing them in Sinhala. Pathum correctly articulated the consequences.

Sinhala medium students get "two advantages" ... they perceive the lesson in Sinhala, and "capture" the English words on the PowerPoint slides... because they know that English is essential outside the university. (Pathum)

Corresponding to the above, almost all the interviewees agreed that they spent relatively more time preparing for EMI classes, especially at the beginning of their EMI career than in their L1 classes. Unlike in EMI classes, the teacher talk in L1 classrooms is, not solely dependent on, or greatly limited to, the PowerPoint slides, the prepared notes or to 
the 'A to Z' written descriptions of the slides. L1 teaching, in contrast, is extensive through examples and anecdotes, given the lecturers' confidence and familiarity in the language. Nine interviewees acknowledged that they were more confident in L1 classes than in EMI, as rightly articulated by Pavani.

When I teach in Sinhala, I am so fluent and "confident" because the lecture is "in my blood", but in EMI classrooms, I get "stuck"...am "confined", and I teach "within a framework”... I use many "examples" in Sinhala medium classroom to explain the lesson, but not in EMI. I know its "unfair by students". (Pavani)

However, two lecturers who had found it very hard to teach in English at the beginning, agreed that currently 'delivering a lecture' in EMI is easier than in L1 contexts, the reason being the prepared PowerPoint slides and their familiarity with the English subject-specific terminology. In addition, for some subjects like Economics, Rosy said it is easy for her to teach in English than in L1 simply because of the absence of subject-specific equivalent vocabulary in Sinhala.

In situations such as those involving the evaluation of examinations and class-based written assignments, all participants overtly or implicitly stressed the importance of leniency and the acceptance of code-mixing and codeswitching in assignments. Mahela revealed how they ignore any grammatical, lexical, and semantic errors in the answers: 'Students tie [original emphasis] some English words, then two or three Sinhala words in between, almost nonsense at times. But as a team we ignored them in evaluating'. Bandara admitted that they ignore language errors: 'we don't reduce marks for language mistakes or errors'. Pavani underscored the importance of leniency even more strongly.

[When] some students write in Sinhala in the middle of their English answers... we as lecturers become so "helpless". We have discussed such issues within the Department and decided to give marks.... If their language is considered for evaluation ... grammar, spellings etc., we "won't be able to give any marks" [meaning we must give zero]. (Pavani)

Rosy justified it by saying that code-mixing is used in lieu of L2 vocabulary. While revealing that student answer in 'Sinhala-English' (an unaccepted variety of English which incorporates many elements of Sinhala), he provides a rationale for the acceptance of such non-academic, non-standard expressions: 'although EMI students understand, they are unable to write [answers] at the exam ... because they can't present their knowledge'. Hence, they are at a 'disadvantage.' To minimise the barrier in writing skills, both Rangga and Chapa suggested extensive group or individual oral presentations as formative assessments. The evaluation practice of leniency and the discretion exercised at individual departments seem quite specific to our study and necessitate future research. Students' non-standard English should be addressed through common national regulations, as Kuteeva $(2020,297)$ contends, along 'the continuum of standard versus nonstandard language uses.'

Another significant finding is setting the examination papers: EMI examination papers are simply the translated versions of the papers set for L1 students. However, Rangga problematized the credibility of the process: 'Setting exam papers in English is not an easy, simple job. We just translate the Sinhala one, but ... whether we do it correctly is skeptical.'

In brief, there are many discrepancies in the system of teaching, and in the process of evaluation in EMI and L1 classrooms. Non-preparation of L1 PowerPoint slides, the arbitrary extension of lecture duration of EMI classes, and the over-dependence on PowerPoint slides for teaching in EMI classes are a few poignant cases in point. Merciful evaluation and using bilingualism in EMI evaluation are potentially wrought with problems. A crucial outcome is the potential for a weaker student to obtain a better grade than a brighter student because of the evaluation mechanism of EMI. This praxis may lead to unjust treatment, by making both the teaching and assessment processes less reliable.

\section{E. Opinions on EMI}

In responding to our inquiry about whether EMI would be an obstacle for the students to perceive and present the abstract and complex concepts in subjects related to humanities and social sciences, many of them considered it as a lapse that can be compensated as students gain a learning context to enhance their English skills. Each of them overtly and intensely communicated the need for EMI programmes for higher education avenues, for career paths, and as ways for internationalisation of the programmes.

Another recurring finding was the dearth of training for EMI lecturers. Despite the majority's perception of the efficacy of the existing EMI programmes, the necessity for continual professional development programmes on EMI for lecturers was highlighted. Four participants also noted that there was a form of resistance to EMI from the non-EMI lecturers, yet it was ignored by the administration and the colleagues, as evidenced through the following testimony.

If we do a special degree, it must be in English. That's my opinion. You know... "without English, we can't do anything" in the future. (Namal)

I have told students that English should not be "allergic" to them (Pavani)

Whatever it takes, learning in English medium is more valuable than studying in Sinhala medium. (Geetha)

Had I studied in English [BA degree], I wouldn't have been [stagnant] in this position today. (Pavani)

Employability opportunities are more in the private sector... English is needed for that. (Bandara)

Yeah ...EMI is needed for all the subjects, because... it's not because I think that English is better than Sinhala. Of course, we have to preserve Sinhala because it's only here... but if we want to get the kind of development in education, we need English (Chapa) 
I blame the university I studied [for my first Degree] for not offering the subjects in English then. (Pavani)

We can hire foreign lecturers through EMI. (Bandara).

I think English should be the national language [to accommodate EMI]. (Namal)

A significant recurring theme of the above excerpts is the overarching importance given to English, by devaluing the learning in L1. The majority while implicitly expressing the disadvantages of learning the content in L1, highlighted that learning in English is prestigious for career, education, and social prestige, concurring with Collins' study (2010). This is an implicit gesture of lack of linguistic power attributed to L1, which bears resemblance to previous studies (Kurkgöz; 2005). Perceptions of this nature may construct an ideology in society that EMI lectures are the only or the main way to provide qualified education in state universities. Moreover, bearing resemblance to previous studies (Skutnabb-Kangas, 2000), such perceptions may construct an impact of attrition on L1 education.

In sum, the findings of our study, partly concurring with previous studies (e.g. Macaro et al., 2018) conclude that the current trend of EMI programmes produces more challenges and issues than opportunities for both higher education of lecturers and students. The goal of EMI in humanities and social sciences is not to enhance L2 proficiency per se, but to give knowledge and skills needed to address the pluralistic social issues in general. Evidently, the lack of English language competence has largely blundered this goal.

\section{CONCLUSION AND IMPLICATIONS}

Given the current trend of globalization in the field of education, the expansion of EMI is inevitable at Sri Lankan universities. When measured quantitatively, the general satisfaction level with EMI - its overall efficacy in developing students' English proficiency and the EMI practices at Sri Lankan universities - appears to have produced generally good results. However, as this study has exposed, the compulsory implementation, the trend of EMI without adequate regard to lecturers' English language proficiency, and the lack of professional development systems have produced several negative outcomes in higher education. If implemented without any empirical evidence, EMI programmes are likely to put the higher education system at risk.

Findings offer insights for future EMI policy implementation not only for Sri Lankan universities, but also for any English as Second Language contexts. First, it is crucial to explicitly measure the level of English proficiency required of lecturers for EMI programmes. Then, administrators, who expand EMI without prior implementation plans, should notice that most EMI problems identified in this study were partly due to its mandatory, ad hoc implementation. Thirdly, higher educational institutions intending to widen/offer EMI programmes need a proper strategic approach to make them effective, both in teaching and assessment.

Hence, replication studies at different English as Second Language contexts would provide data that may be applied to design an effective implementation strategy for EMI policy. This paper provides an analysis of the EMI practices and lecturers' perceptions at Sri Lankan universities, which can serve as a point of reference for scholars and educators in any English as L2 context.

\section{REFERENCES}

[1] Airey, J. (2020). The content lecturer and English-medium instruction (EMI): epilogue to the special issue on EMI in higher education. International Journal of Bilingual Education and Bilingualism, 23(3), 340-346.

[2] Airey, J. (2012). 'I Don't Teach Language.' The Linguistic Attitudes of Physics Lecturers in Sweden. AILA Review, 25, 64-79.

[3] Airey, J., \& Linder, C. (2006). Language and the experience of learning university physics in Sweden. Institute of Physics Publishing, 27, 553-560.

[4] Altbach, P. (2004). Globalization and the university: Myths and realities in an unequal world. Tertiary Education and Management, 10, 3-25.

[5] Ammon, U., \& McConnell, G. (2002). English as an academic language in Europe: A survey of its use in teaching. Bern: Peter Lang.

[6] Attanayake, A.U. (2018). Undergraduate ELT in Sri Lanka: Policy, Practice and Perspectives for South Asia, Newcastle: Cambridge Scholars Publishing.

[7] Basturkmen, H., \& Shackleford, N. (2015). How Content Lecturers Help Students with Language: An Observational Study of Language related Episodes in Interaction in First Year Accounting Classrooms. English for Specific Purposes, 37, 87-97.

[8] Belhiah, H., \& Elhami, M. (2015). English as a Medium of Instruction in the Gulf: When Students and Teachers Speak. Language Policy, 14(1), 3-23.

[9] Berriz, B. (2006). Unz got your tongue: What have we lost with the English-only mandates? Radical Teacher, 75(1), 10-15.

[10] Björkman, B. (2009). From Code to Discourse in Spoken ELF. In A. Mauranen \& E. Ranta (Eds.) English as a Lingua Franca: Studies and Findings (pp. 225-251). Newcastle: Cambridge Scholars Press.

[11] Björkman, B. (2011). Pragmatic Strategies in English as an Academic Lingua Franca: Ways of Achieving Communicative Effectiveness? Journal of Pragmatics, 43 (4), 950-964.

[12] Byun, K., Chu, H., Kim, M., Park, I., Kim, S., \& Jung, J. (2011). English medium teaching in Korean higher education: Policy debates and reality. Higher Education, 62, 431-449.

[13] Coleman, J. A. (2006). English-medium teaching in European higher education. Language Teaching, 39(1), 1-14.

[14] Dearden, J. (2015). English as a medium of instruction: A growing global phenomenon. London: British Council. Retrieved July 7, 2016 from https:// www.britishcouncil.org/education/ihe/knowledge-centre/english-languagehigher-education/reportenglish-medium-instruction 
[15] Dearden, J., \& Macaro, E. (2016). Higher Education Teachers' Attitudes Towards English Medium Instruction: A three Country Comparison. Studies in Second Language Learning and Teaching 6(3), 455-486.

[16] Department of Census and Statistics (2014). Brief analysis of population and housing characteristics: Population and housing census in Sri Lanka. Retrieved March 27, 2020 from www.statistics.gov.lk

[17] Department of Examinations of Sri Lanka. Statistics and Performance Indices. Retrieved March 27, 2020 from https://doenets.lk/statistics

[18] Dimova, S., Hultgren, A.K. \& Jensen, C. (2015). English-Medium Instruction in European Higher Education. English in Europe, 3. Berlin: De Gruyter Mouton.

[19] Doiz, A. \& Lasagabaster, D. (2020). Dealing with language issues in English-medium instruction at university: a comprehensive approach, International Journal of Bilingual Education and Bilingualism, 23(3), 257-262.

[20] Erling, E. J., \& Hilgendorf, S. K. (2006). Language policies in the context of German higher education. Language Policy, 5 , 267-292.

[21] Evans, S., \& Morrison, B. (2011). Meeting the challenges of English medium higher education: The first-year experience in Hong Kong. English for Specific Purposes, 30(3), 198-208.

[22] Farrell, L., \& Giri, R. A. (2011). English education in South Asia: The challenges of globalisation. In L. Farrell, U. N. Singh, \& R. A. Giri (Eds.), English language education in South Asia (pp.13-23). New Delhi, India: Cambridge University Press.

[23] Global Ranking of Countries and Regions. (2019). The world's largest ranking of countries and regions by English skills. Retrieved May 10, 2020 from https://www.ef.com/wwen/epi/

[24] Graddol, D. (2005). The future of English. The British Council: London.

[25] Graddol, D. (2006). English Next. London: British Council.

[26] Hamid, M. O. \& Jahan, I, (2015). Language, identity, and social divides: Medium of instruction debates in Bangladeshi print media. Comparative Education Review 59(1), 75-101.

[27] Hoare, P. (2003). Effective teaching of science through English in Hong Kong secondary schools [Doctoral dissertation]. University of Hong Kong.

[28] Hornberger, N., \& Vaish, V. (2009). Multilingual language policy and school linguistic practice: Globalization and English language teaching in India, Singapore and South Africa. Compare, 39(3), 305-320.

[29] Huang, D.F. (2015). Exploring and assessing effectiveness of English medium instruction courses: The students' perspectives. Procedia-Social and Behavioral Sciences, 173, 71-78.

[30] Jiang, L., Zhang, L.J., \& May, S. (2019). Implementing English medium instruction (EMI) in China: teachers' practices and perceptions, and students' learning motivation and needs, International Journal of Bilingual Education and Bilingualism, 22(2), $107-11$.

[31] Kang, S.-Y., \& Park, H.-S. (2004). Student beliefs and attitudes about English medium instruction: Report of questionnaire study. Yonsei Review of Educational Research, 17(1), 33-53.

[32] Thirunavukkarsu, K. (2009). Reintroduction of English as medium of instruction in Sri Lanka: with special reference to Jaffna. International Journal of English Language and Literature Studies, 1(1), 1-8.

[33] Kaur, J. (2009). Pre-empting Problems of Understanding in English as a Lingua Franca. In A. Mauranen \& E. Ranta (Eds.) English as a Lingua Franca: Studies and Findings, (pp.107-124). Newcastle: Cambridge Scholars.

[34] Kim, J., \& Tartar, B. (2018). A case study of international instructors' experiences of English-medium instruction policy in a Korean university. Current issues in language planning, 19(4), 401-415

[35] Kim, J., \& Tatar, B. (2017). Nonnative English-speaking professors' experiences of English-medium instruction and their perceived roles of the local language. Journal of Language, Identity \& Education, 16(3), 157-171.

[36] Kim, J., Tatar, B., \& Choi, J. (2014). Emerging culture of English medium instruction in Korea: Experiences of Korean and international students. Language and Intercultural Communication, 14(4), 441-459.

[37] Kırkgöz, Y. (2013). Students' approaches to learning in an English medium higher education. The Journal of Language Teaching and Learning, 2, 30-39.

[38] Kurkgöz, Y. (2005). Motivation and Student Perception in an English medium Instruction. Journal of Languages and Linguistic Studies 1, 101-123.

[39] Kirkgöz, Y. (2009). Students' and Lecturers' Perceptions of the Effectiveness of Foreign Language Instruction in an Englishmedium University in Turkey. Teaching in Higher Education 14(1), 81-93.

[40] Kirkgöz, Y. (2014). Students' Perceptions of English Language Versus Turkish Language Used as the Medium of Instruction in Higher Education in Turkey. Turkish Studies, 9(12), 443-459.

[41] Klaassen, R. G., \& Graaff, E. D. E. (2001). Facing innovation: Preparing lecturers for English-medium instruction in a nonnative context. European Journal of Engineering Education, 26(3), 281-289.

[42] Krashen, S. (1985). The Input Hypothesis: Issues and Implications. London: Longman.

[43] Kuteeva, M. (2020). Revisiting the 'E' in EMI: students' perceptions of standard English, lingua franca and translingual practices, International Journal of Bilingual Education and Bilingualism, 23(3), 287-300.

[44] Lassegard, J. P. (2006). International student quality and Japanese higher education reform. Journal of Studies in International Education, 10(2), 119-140.

[45] Macaro E., \& Akincioglu, M. (2018). Turkish university students' perceptions about English Medium Instruction: exploring year group, gender and university type as variables, Journal of Multilingual and Multicultural Development, 39(3), 256-270.

[46] Macaro E. et. Al (2018). A systematic review of English medium instruction in higher education, Language Teaching, 51(1), $36-76$.

[47] Maiworm, F., \& Wächter, B. (2002). English-Language-taught degree programmes in European Higher Education: Trends and success factors. Bonn: Lemmens.

[48] Manakul, W. (2007). Role of English in internalization of higher education: The case of the Graduate School of Engineering, Hokkaido University. Higher Education and Lifelong Learning, 15,155-162.

[49] Mauranen, A. (2009). Chunking in ELF: Expressions for Managing Interaction. Intercultural Pragmatics, 6(2), $217-233$. 
[50] Medawattegedera, V. V. (2011). 'Shots of Justice' English medium instruction in Sri Lankan secondary schools: from policy to practice [Doctoral dissertation]. Ulster University. Retrieved April 5, 2019 from https://ethos.bl.uk/

[51] Meierkord, C. (2013). Interpreting Successful Lingua-franca Interaction. An analysis of Non-native-/non-native Small Talk Conversation in English. Linguistics Online, 5(1). Retrieved March 30, 2020 from https://bop.unibe.ch/linguistikonline/article/view/1013

[52] Naun, D. (2003). The impact of English as a global language on educational policies and practices in the Asia-pacific region. TESOL Quarterly, 37(4), 589-613.

[53] Ong, K. W. K., Zhang, L. J. \& Martin, I. P. (2013). Codeswitching in Universities in Singapore and the Philippines. In R. Barnard \& J. McLellan (Eds.), Code switching in University English-Medium Classes: Asian Perspectives, (pp. 163-174). Bristol: Multilingual Matters.

[54] Phillipson, R. (2001). English for globalisation or for the world's people? International Review of Education, 47,185-200.

[55] Sánchez-Pérez, María del Mar, ed. (2020). Teacher Training for English-Medium Instruction in Higher Education. Pennsylvania: IGI Global.

[56] Sert, N. (2008). The language of instruction Dilemma in the Turkish context. An International Journal of Educational Technology and Applied Linguistics, 36(2), 156-171.

[57] Skutnabb-Kangas,T. (2000). Linguistic genocide in education or worldwide diversity and human rights? Mahwah NJ: Lawrence Erlbaum.

[58] Soruç, A., \& Griffiths, C. (2018). English as a medium of instruction: Students' strategies. ELT Journal, 72(1), 38-48.

[59] Stroud, C., \& Wee, L. (2005). Style, identity and English language literacy. Linguistics and Education, 16, 319-337.

[60] Toribio, A. J. (2004). Convergence as an Optimization Strategy in Bilingual Speech: Evidence from Code-Switching. Bilingualism: Language and Cognition, 7(2), 165-173.

[61] Tsuneyoshi, R. (2005). Internationalization strategies in Japan. Journal of Research in International Education, 4(1), 65-86.

[62] Universities Act. (1978). No. 16 of 1978. Retrieved March 18, 2020 from www.ugc.ac.lk

[63] University Grants Commission. (2019). Strategic proposal of Higher Education Expansion and Development (AHEAD). Retrieved April 5, 2020 from www.ugc.ac.lk

[64] Vinke, A. A. (1995). English as the medium of instruction in Dutch Engineering education [Doctoral dissertation]. Delft University of Technology. Retrieved April 8, 2018 from http://repository.tudelft.nl/islandora/ object/uuid:491b55f9-fbf9-4650a44d-acb9af8412a8?collection $=$ research

[65] Vinke, A. A., Snippe, J., \& Jochems, W. (1998). English-medium content courses in non-English Higher Education: A study of lecture experiences and teaching behaviours. Teaching in Higher Education, 3(3), 383-394.

[66] Wa"chter, B., \& Maiworm, F. (2008). English-taught programmes in European higher education: ACA Papers on International Cooperation in Education. Bonn: Lemmens.

[67] Wedikkarage, L. (2009). Language and power: The implications of language for peace and development, Dar es Salaam: Mkukina Nyota Publishers.

[68] Wright, S. (2004). Language policy and language planning: From nationalism to globalisation. Palgrave Macmillan: London.

[69] Yang, W. (2015). Content and language integrated learning next in Asia: Evidence of learners' achievement in CLIL education from a Taiwan tertiary degree programme. International Journal of Bilingual Education and Bilingualism, 18(4), 361-382.

[70] Zhang, Z. (2017). English-medium instruction policies in China: Internationalisation of higher education. Journal of Multilingual and Multicultural Development, 39(6), 542-555.

Chitra Jayathilake (corresponding author) is a Senior Lecturer in English at the Department of English and Linguistics, University of Sri Jayewardenepura, Sri Lanka. She holds a PhD in English from the University of Keele, UK, an MA in TESL from the PGIE, Open University, SL and an MA in Linguistics from Kelaniya University, SL.

Sujeewa Hettiarachchi is a Senior Lecturer at the Department of English and Linguistics, University of Sri Jayewardenepura, Sri Lanka. He holds an MA and a PhD in Linguistics from the University of Michigan and an MA in TESOl from Eastern Michigan University, USA.

Sujeeva S. Pereira is a Senior Lecturer at the Department of English and Linguistics, University of Sri Jayewardenepura, Sri Lanka. She holds a PhD from the University of Colombo, SL, an MA in Applied Linguistics from the University of Newcastle, Australia, and an MA in Linguistics from Kelaniya University, SL. 